\title{
Monoamines and Kynurenine Involvement in Pathogenetic Mechanisms of Attention Deficit Hyperactivity Disorder or Hyperkinetic Syndrome
}

\author{
Marat Uzbekov*, Eduard Misionzhnik and Irina Strelkova \\ Department of Brain Pathology Moscow Research Institute of Psychiatry, Moscow, Russia.
}

Submission: November 30, 2018; Published: December 19, 2018

*Corresponding author: Marat Uzbekov, Moscow Research Institute of Psychiatry, Poteshnaya 3, 107076 Moscow, Russia

\begin{abstract}
Background: Pathogenetic mechanisms of attention deficit hyperactivity disorder (ADHD) or hyperkinetic syndrome (HKS) are not clear. The aim was to identify possible clinical and biochemical (monoaminergic) correlates of ADHD/HKS.

Methods: The levels of monoamines, their metabolites and kynurenine metabolite in urine samples were estimated using fluorometric and chromatographic methods.

Results: It was found that ADHD/HKS is followed by activation of dopaminergic and inhibition of noradrenergic systems. 3 weeks of psychostimulant - sydnocarb treatment had improved children's clinical status that was followed by decrease of dopaminergic and serotonergic system activities. Sydnocarb therapy has revealed reciprocal relationship between serotonergic and kynurenine systems.

Conclusion: Symptom improvement in ADHD/HKS children is followed by an activation of the kynurenine system. We propose a hypothesis that the kynurenine system plays significant role in the pathogenetic mechanisms of ADHD/HKS. We want to draw attention that these results were received using sample size of 42 patients. Thus, it is necessary to perform such kind investigations on the more representative and larger samples.
\end{abstract}

Keywords: Attention deficit hyperactivity disorder; Hyperkinetic syndrome; Children; Dopamine; Serotonin; kynurenine; Psychostimulant sydnocarb

\section{Introduction}

From the 1970s, a considerable number of investigations have been undertaken in which the authors have tried to reveal the pathogenetic mechanisms of ADHD, according to Diagnostic and Statistical Manual, fifth edition (DSM-5) [1] or hyperkinetic syndrome (HKS), according to International Classifications of Diseases, tenth edition, clinical modification (ICD-10-CM) [2].

The aetiology of ADHD/HKS is not known and pathogenesis is not clear. It has been shown that changes in the central monoaminergic systems play important role in ADHD/HKS [3,4]. Campbell M and Spenser E.K [5] wrote that "It remains to be shown where discrete biochemically - based subgroups show a different response to drugs: to psychostimulants, imipramine or neuroleptics" (p. 273). In spite that it was written 30 years ago the problem still remains urgent.

We decided to identify possible clinical-biochemical correlates of ADHD/HKS using a number of urinary biochemical indices that reflect catecholamine and serotonin neurotransmitter metabolism. Of particular interest is the detection of specific features of monoamine metabolism correlating with ADHD/ HKS severity. It is supposed that such kind of approach may be useful both in the understanding of the pathogenetic mechanisms of ADHD/HKS and in selecting pathophysiologically reasoned psychopharmacological tactics of the therapy of ADHD/HKS patients with different severity of condition.

\section{Subjects and Methods}

As a whole there were examined 42 children with ADHD/ HKS. In compliance with the degree of motor hyperactivity and inattention, two groups of children with HKS were selected. Children of group 1 (mild HKS, mHKS) consisted of 6 patients with mild motor hyperactivity and inattention in which the emotional disturbances manly took the form of emotional liability. Group 2 included 6 patients with severe form of HKS (sHKS). Children of this group were characterized by excessive motor activity, pronounced inattention and affective disorders; insignificant environmental stimuli caused affective outbursts with aggression and a tendency to destructions [6]. Both these groups consisted of patients with borderline intellectual disability (BID) (according to DSM-5). Group 3 (control) consisted of 8 patients without any features of HKS (in all groups the patients were 7-11 years old children). Clinical delineation of different ADHD/HKS forms was carried out as described in [7]. 
We consider that the most spare and convenient approach in our study is urine investigation. Methods for the determination of monoamines, their metabolites and N-methylnicotinamide (one of the main metabolites of kynurenine pathway of tryptophan metabolism) in urine samples were described elsewhere [6].

\section{Results and Discussion}

It was shown that mHKS in comparison with the controls was characterized by significant increase of dopamine (DA) excretion by $165 \%(\mathrm{p}<0.001)$ and a decrease of noradrenaline (NA) excretion by $46 \%(\mathrm{p}<0.001)$. In sHKS children DA and L-dopa excretion were significantly increased by $432 \%$ and $124 \%$ (both $\mathrm{p}<0.001$ ), respectively, whereas excretion of NA did not change in comparison with control group. It was found that there are significant differences between severe and mild form of HKS. We can conclude that HKS is followed - within limits - by activation of dopaminergic system and inhibition of noradrenergic system. It has to take into the account that this conclusion is based only on the sample of 42 children. Further investigations are necessary on the larger sample sizes.

The therapy of ADHD/HKS is a complex problem. For several decades the psychostimulants (primarily, methylphenidate and amphetamine) are the most frequently used ADHD treatments $[8,9]$. In the 1970s, the psychostimulant Sydnocarb [3-(ß-phenylisopropyl)-N-phenyl-carbamoyl-sydnonimine] was synthesized and introduced in clinical practice in the Soviet Union as an effective treatment of child HKS $[7,10]$. It was shown by Krasov [7] that treatment mHKS children with sydnocarb was effective in $94 \%$ of cases whereas such kind of treatment of sHKS children was effective only in $24 \%$ of cases.

We have investigated the state of monoaminergic systems in children with mild HKS form under sydnocarb treatment. Patients were divided in 2 groups: mHKS with normal intellect (18 boys) and mHKS with BID (12 boys). Patients received 5-15 mg sydnocarb (daily during 1-1.5 months) (for ethical reasons sHKS children were not included in the study). There were similar changes in the level of daily excretion of monoamine metabolites in both groups. Thus, after psychostimulant medication, homovanillic acid (HVA) excretion decreased by 55\% ( $p<0.001)$ and $29 \%$. Our results show that the improved clinical status of HKS children under psychostimulant sydnocarb treatment at least partially coincided with a decrease of dopaminergic activity.

The data about the involvement of serotonin in pathogenetic mechanism of ADHD/HKS are controversial [11]. We have shown that there were no significant changes in 5-hydroxiindoleacetic acid (5-HIAA) excretion in children with mild and severe HKS forms in comparison to controls [6]. However, 3 weeks after sydnocarb medication, we found a significant decrease in 5-HIAA excretion in both groups, by $61 \%(\mathrm{p}<0.001)$ and $39 \%(\mathrm{p}<0.01)$, respectively. This indirectly points to a potential decrease of serotonin levels in the brain. Thus sydnocarb treatment has revealed serotonin involvement in pathogenesis of ADHD/HKS.
This is supported by data that the paradoxical calming effect of psychostimulant treatment on the increased locomotor activity in the animal model was dependent on serotonergic activity [12].

It has been shown [13] that the kynurenine pathway of the metabolism of tryptophan, the precursor molecule in both the serotonin and the kynurenine metabolic pathways, is the main one found in mammals: about $90-95 \%$ of tryptophan molecules are metabolized via this pathway and only about $5-10 \%$ of these molecules are used for serotonin synthesis. We have examined the possible involvement of kynurenine pathway in the HKS pathogenetic mechanisms. It was found that HKS children under sydnocarb treatment were characterized by an increase of N-MNA excretion by $34 \%$ and $28 \%$ ( $p<0.05$ both groups), respectively. The N-MNA/5-HIAA ratio under sydnocarb medication increased 2.03.5 times. These data indicate that under sydnocarb treatment, the kynurenine pathway of tryptophan metabolism begins to prevail to an even greater extent over serotonin pathway of tryptophan metabolism. This could lead to the observed decrease of serotonergic activity following medication, and this was followed by the improvement of clinical status of HKS children. There are data that some kynurenine metabolites (L-kynurenine, 3-hydroxykynurenine, picolinic acid) formed along the kynurenine pathway possess the ability to inhibit locomotor activity in animals Itn [13]. Their views are in part supported by results of Gainetdinov et al. [12]. We can hypothesize that increased urine excretion of kynurenine metabolite - N-MDA as well as N-MNA/5-HIAA ratio can serve as predictors of the efficacy of psychostimulant medication.

In conclusion, we propose s hypothesis that the kynurenine system plays significant role in the pathogenetic mechanisms of ADHD/HKS. Accordingly, ADHD/HKS might be characterized by an activation of serotonergic and an inhibition of kynurenine systems. Symptom improvement in ADHD/HKS children is followed by an activation of the kynurenine system. Our investigation indicates that ADHD/HKS is characterized by profound disturbances and dysregulation of monoamine metabolism.

\section{Limitations}

There are some limitations of the study.

i. It is necessary to have larger sample size.

ii. It will be useful to examine some other parameters of kynurenine pathway.

iii. For more precise understanding the mechanisms of serotonin involvement in pathogenesis of ADHD/HKS it will be useful the direct measurements of serotonin in the platelets.

\section{Acknowledgement}

We are grateful for Dr Victor Krasov, MD, for dividing investigated groups. We would like to express our sincere gratitude to Mrs Olga Fedorova and Lena Skokina for technical assistance. 


\section{Global Journal of Intellectual \& Developmental Disabilities}

\section{References}

1. American Psychiatric Association (2013) Diagnostic and Statistical Manual of Mental Disorders ( $5^{\text {th }}$ edn). Chapter Neurodevelopmental disorders, APA, Washington, USA.

2. World Health Organization (2015) International Classification of Diseases and Related Problems. (10 ${ }^{\text {th }}$ edn) Clinical Modification, WHO, Geneva, Switzerland.

3. Shekim WO, Javaid J, Dans JM, Bylund DBM (1983) Urinary MHPG and HVA excretion in boys with attent6ion deficit disorder and hyperactivity treated with d-amphetamine. Biol Psychiatry 18(6): 707-714.

4. Zametkin AJ, Karoum F, Linnoila M, Rapoport JL, Brown GL, et al. (1985) Stimulants, urinary catecholamines, and indoleamines in hyperactivity A comparison of methylphenidate and dextroamphetamine. Arch Gen Psychiatry 26: 251-255.

5. Campbell M, Spencer EK (1988) Psychopharmacology in children and adolescent psychiatry: A review of the past five years. J Am Acad Child Adolesc Psychiatry 27: 269-279.

6. Uzbekov MG, Misionzhnik EY (2003) Changes in urinary monoamine excretion in hyperkinetic children. Hum Psychopharmacol Clin Exp 18 493-497.

This work is licensed under Creative Commons Attribution 4.0 License DOI: 10.19080/GJIDD.2018.05.555667
7. Krasov VA (1988) Sydnocarb treatment of junior school age children with hyperdynamic syndrome. Zh Nevrol Psychiatr SS Korsakova 88: 97-101.

8. Zametkin AJ, Ernst M (1999) Problems in the management of attentiondeficit hyperactivity disorder. N Engl J Med 340: 40-46

9. Volkow ND, Swanson JM (2003) Variables that affect the clinical use and abuse of methylphenidate in the treatment of ADHD. Am J Psychiatr 160: 56-65.

10. Afanas'ev I, Anderzhanova E, Kudrin V, Rayevsky K (2001) Effects of amphetamine and sydnocarb on dopamine release and free radical generation in rat striatum. Pharmacol Biochem Behav 69: 653-658.

11. Oades RD, Sadile AG, Sagvolden T, Viggiano D, Aase H, Zuddas A, et al (2005) The control of responsiveness in ADHD by catecholamines: evidence for dopaminergic, noradrenergic, and interactive roles. Dev Sci 8: 122-131.

12. Gainetdinov RR, Wetsel WC, Jones SR, Levin ED, Jaber M, et al. (1999) Role of serotonin in the paradoxical calming effect of psychostimulants on hyperactivity. Science 3: 397-401.

13. Lapin IP (2004) Stress-anxiety-depression-alcoholizm-epilepsy (Neurokynine mechanisms and new approaches to the treatment. Dean, St. Peterburg, Russia.

\section{Your next submission with Juniper Publishers will reach you the below assets}

- Quality Editorial service

- Swift Peer Review

- Reprints availability

- E-prints Service

- Manuscript Podcast for convenient understanding

- Global attainment for your research

- Manuscript accessibility in different formats

( Pdf, E-pub, Full Text, Audio)

- Unceasing customer service

Track the below URL for one-step submission https://juniperpublishers.com/online-submission.php 